\title{
Effective identification of cancer predisposition syndromes in children with cancer employing a questionnaire
}

\author{
Miriam Schwermer ${ }^{1} \cdot$ Astrid Behnert $^{1} \cdot$ Beate Dörgeloh ${ }^{1} \cdot$ Tim Ripperger $^{2} \cdot$ Christian P. Kratz $^{1,3}$ (C)
}

Received: 4 October 2020 / Accepted: 5 February 2021 / Published online: 2 March 2021

(c) The Author(s) 2021

\begin{abstract}
Approximately $10 \%$ of children with newly diagnosed cancer have a cancer predisposition syndrome (CPS). The optimal diagnostic approach to identify them among children diagnosed with cancer is unknown. Objective: To determine whether the use of a one-page questionnaire can improve the CPS diagnosis among children with an oncologic condition. Design: Comparative effectiveness research. Setting: Referral center for children with cancer. Results: 739 children diagnosed with an oncologic condition between 2012 and 2019. All children with a newly diagnosed oncologic condition presenting to Hannover Medical School between January 1st 2017 and December 31st 2019 were prospectively evaluated with a CPS questionnaire. Children in whom the questionnaire suggested the need of a genetic workup were further evaluated. All children diagnosed with an oncologic condition between January 1st 2012 and December 31 st 2016 served as control. The CPS diagnoses established during both time periods were evaluated and compared. A CPS was diagnosed in 27 out of 287 children (9.4\%) during the questionnaire period versus 24 out of 452 children $(5.3 \%)$ during the control period $(P=0.032)$. Conclusion: The CPS questionnaire appears to significantly improve the diagnosis of children with CPS among children with a newly diagnosed oncologic condition.
\end{abstract}

Keywords Cancer predisposition syndromes · Questionnaire · Pediatric cancer

\section{Introduction}

Cancer predisposition syndromes (CPS) are a major cause of childhood cancer. Several next generation sequencing (NGS) studies have shown that the proportion of children with cancer who have a CPS is larger than previously anticipated [1-3]. Given the clinical relevance of a CPS in a child with cancer (e.g., counseling, psychologic support, prevention, surveillance, treatment, and identification of relatives at risk), a small number of centers screen for the presence of a CPS by offering a genetic evaluation and (epi)genetic testing of germline DNA to all patients; however, this resource is only available to a small number of centers or to children

Christian P. Kratz

kratz.christian@mh-hannover.de

1 Pediatric Hematology and Oncology, Hannover Medical School, Hannover, Germany

2 Department of Human Genetics, Hannover Medical School, Hannover, Germany

3 Rare Disease Program, Hannover Medical School, Hannover, Germany with selected entities (e.g., in Germany, all children with brain tumors are currently being offered testing through the brain tumor studies).

In order to guide pediatric oncologists to decide which patients have a high probability of an underlying CPS and would benefit from genetic counseling and testing, we and others have developed questionnaires and mobile apps [4-7]. Based on clinical features, previous cancer (family) history, cancer sub-type, and somatic mutational spectrum, it is decided on whether a genetic evaluation is indicated. Here, we show that use of one of such tools [5] is associated with a significant increase of CPS diagnoses among children with a newly diagnosed oncologic condition.

\section{Methods}

The previously described questionnaire (see Supplement and reference [5]) originally developed by Jongmans and colleagues [4] and updated by the cancer predisposition working group of the German Society of Pediatric Oncology and Hematology with input from various trial groups [5] 
Fig. 1 Relative frequencies of pediatric cancer types. a Shows the distribution of pediatric cancer types diagnosed at Hannover Medical School between 2017 and $2019(n=287)$; b shows the distribution of pediatric cancer types diagnosed at Hannover Medical School between 2012 and $2016(n=452)$; $\mathbf{c}$ shows the distribution of pediatric cancer types reported to the German Childhood Cancer Registry between 2009 and $2018(\mathrm{n}=21,831)$ [8]. BT bone tumors, $G C T$ germ cell tumors, $H T$ hepatic tumors, $P N S$ peripheral nervous cell tumors, $R B$ retinoblastoma, $R T$ renal tumors, $S T S$ soft tissue sarcomas

was prospectively employed in all 287 children presenting with an oncologic condition to Hannover Medical School during a 3-year period (i.e., 2017-2019). All children who were diagnosed with an oncologic condition within the prior 5 -year period when the questionnaire was not applied (i.e., 2012-2016, $n=452$ ) served as control. Children with a questionnaire result indicating the presence of a CPS (i.e., $\geq 1$ fulfilled criterion from the questionnaire) were further evaluated by a CPS specialist (i.e., an oncologist with expertise in genetics or a geneticist with expertise in cancer predisposition) to determine whether further genetic testing was warranted. Only if this initial genetic evaluation revealed that the genetic testing criteria of a known CPS were met, genetic counselling and testing was offered. The CPS diagnoses established during the questionnaire and control periods were compared. We employed Pearson's $\chi^{2}$ test and a $P$ value lower than 0.05 was regarded as statistically significant. The study was approved by the ethical review board at Hannover Medical School.

\section{Results}

Figure 1 depicts the distribution of pediatric cancer types diagnosed at Hannover Medical School within the questionnaire and the control periods. The cancer distribution during both study periods are similar and resemble the pediatric cancer spectrum captured by the German Childhood Cancer Registry between 2009 and 2018 [8]. In 86 out of 287 children $(30 \%)$ the questionnaire indicated a high likelihood of an underlying CPS. After expert review, 20 of the 86 patients were not further evaluated because the clinical constellation appeared unlikely to be associated with a currently known CPS (e.g., the questionnaire was positive but the testing criteria for a known CPS were not met). Of the remaining 66 patients, 3 declined further evaluation, 3 were not evaluated due to the patient's death or the family's relocation. The remaining 60 patients were offered counseling and testing and a CPS was diagnosed (or known prior to the cancer diagnosis) in 27 patients based on germline testing $(9.4 \%$ of
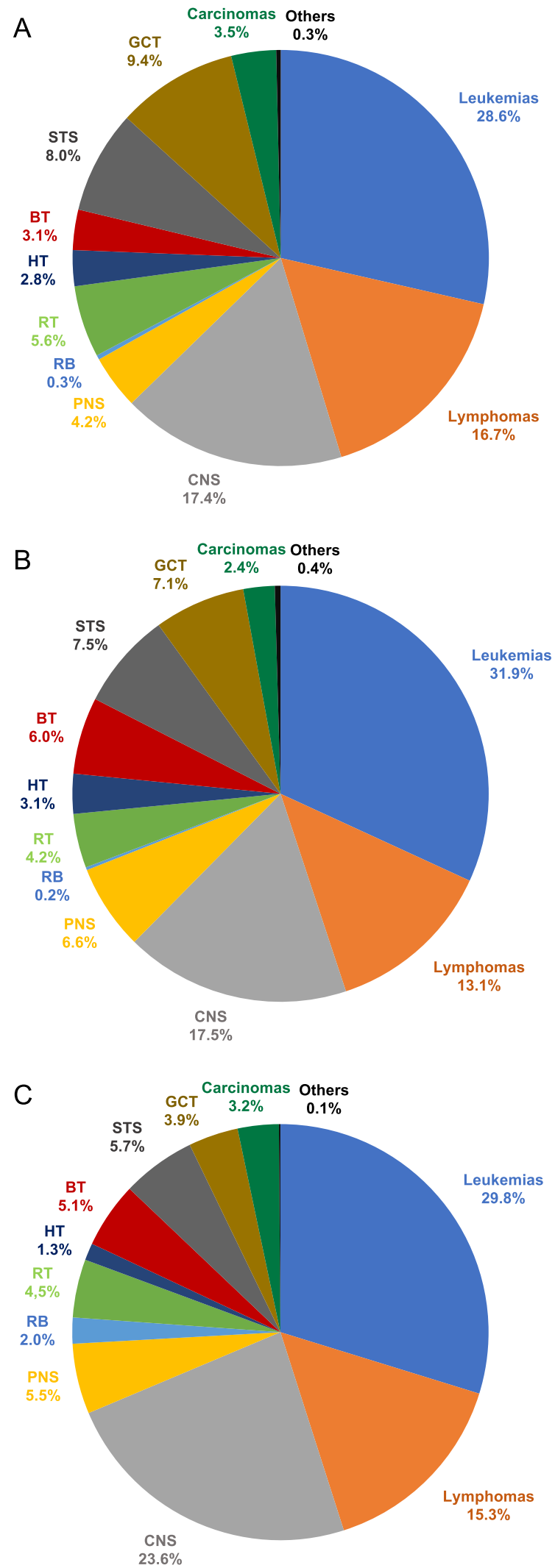
the entire group and $45 \%$ of the patients that were offered counseling and testing). In contrast, among the 452 patients who were diagnosed with an oncologic condition during the control period, a CPS diagnosis was established (or known prior to the cancer diagnosis) in 24 patients (5.3\%). When comparing both groups, the number of patients diagnosed with a CPS was significantly higher during the questionnaire period than the number of CPS patients diagnosed during the control period $(P=0.032)$. It can be assumed that all patients in whom the CPS diagnosis was established prior to the cancer diagnosis or presentation to our department (e.g., Down syndrome, Neurofibromatosis type 1 would have been detected clinically when the patients presented with the oncologic condition. Nevertheless, conservatively excluding these CPS patients from the analysis, the difference remains significant. After exclusion of these previously known CPS cases, 13 CPS among 287 patients were diagnosed during the questionnaire and 7 CPS among 452 patients during the control period $(P=0.015)$. Tables 1 and 2 show details on individual CPS patients diagnosed during both periods. Notably, one patient suffered from a mitochondrial liver disease caused by germline defects of TRMU [9]. Although this condition is not an established CPS, we assume that the liver tumor that occurred in that patient was caused by the underlying liver condition. Four patients have been described elsewhere [10-13].

\section{Discussion}

Here, we show that the systematic use of a CPS questionnaire [5] was associated with a significant increase of CPS diagnoses among children with a newly diagnosed oncologic condition. The proportion of children diagnosed with a CPS using this clinical approach resembles the proportion of children diagnosed by (epi)genetic testing [1-3], suggesting that not many children with a CPS are being overlooked using this approach. However, in order to define the negative and positive predictive values and sensitivity/specificity of the questionnaire the study design would need to include both, agnostic (epi)genetic testing and the questionnaire. The questionnaire approach, by definition, misses children with hidden or atypical CPS features (e.g., a patient with Li-Fraumeni syndrome with a de novo variant in TP53 and osteosarcoma would not be detected through this approach). Also, children with subtle features of a CPS may be missed if patients are not evaluated by an experienced dysmorphologist. Most patients in whom a CPS diagnosis was established had oncologic conditions that by itself suggested the presence of a CPS diagnosis when observed in childhood (e.g., cystic nephroma, meningioma, gastrointestinal stromal tumor, myelodysplastic syndrome) or obvious physical features leading to the CPS diagnosis (e.g., lateralized overgrowth).

One potential advantage of the questionnaire approach is the preferential identification of children with a clinically relevant CPS. In contrast, a genetic evaluation and agnostic (epi)genetic testing offered to all children with cancer has the probability of identifying gene variants in known or scientifically suspected CPS genes with unknown clinical relevance (e.g., heterozygous variants in recessive cancer genes or variants in cancer genes predisposing to malignancy during adulthood). While this knowledge is of high scientific interest, it may not influence the clinical care and may have potential adverse effects (anxiety, costs).

The study has several limitations: (1) The study took place in a center with special interest in CPS. Thus, the CPS diagnoses during both time periods may have been influenced and improved by this expertise. This factor may have led to the observation that even in the control period, rare CPS were identified $[12,13]$. (2) A further genetic evaluation was initiated only in situations when it appeared likely that a known CPS could explain the clinical situation. Thus, the likelihood of making novel discoveries was decreased. (3) Several patients were diagnosed with a CPS prior to the development of cancer, however, when we exclude these patients from the analysis, the results remained significant. (4) We cannot rule out that the study is influenced by coincidental factors, for example, a small number of additional cancer types highly associated with a CPS during the control period may have led to different results. (5) The list of CPS as well as awareness are constantly growing [14-16]. These factors could have led to more CPS diagnoses during the later questionnaire period.

\section{Conclusion}

Despite these limitations, our data suggest that tools like a CPS questionnaire may significantly improve the diagnosis of CPS among children with cancer. Although negative 
Table 1 Individuals diagnosed with CPS employing the screening tool (2017-2019)

\begin{tabular}{|c|c|c|c|c|c|c|}
\hline No. & Cancer & A@D & Sex & Reason for evaluation & Genetic cause & CPS \\
\hline $1^{\mathrm{b}}$ & ALL & 3.4 & M & Physical features & Trisomy 21 & DS \\
\hline $2^{b}$ & ALL & 6.1 & M & Physical features developmental delay & $\begin{array}{l}\text { ATM, c.3576G > A p. (Ser1135_Lys- } \\
\text { 1192del58), homozygous, aberrant } \\
\text { splicing }\end{array}$ & AT \\
\hline 3 & $\mathrm{CN}$ & 1.1 & M & Pathology & $\begin{array}{l}\text { arr [GRCh37] 14q32.12q32.2 } \\
\quad(9450372296382117) \times 1 \text {, deletion } \\
\text { including DICER1 }\end{array}$ & DICER1 syndrome \\
\hline $4^{\mathrm{b}}$ & FH & 0.3 & M & Physical features & $N F 1$, c. 4812 C $>$ A p. $(\operatorname{Tyr} 1604 *)$ & NF1 \\
\hline 5 & GIST & 14.11 & M & Pathology & SDHA, c.688del p. (Glu230Serfs*10) & HPPS \\
\hline 6 & GB & 9.9 & $\mathrm{~F}$ & $\begin{array}{l}\text { Physical features, consanguinity, } \\
\text { pathology }\end{array}$ & $\begin{array}{l}\text { MSH6, c.691delG p. (Val231Tyrfs*15), } \\
\text { homozygous }\end{array}$ & CMMRD \\
\hline $7^{\mathrm{b}}$ & GB & 11.0 & $\mathrm{~F}$ & $\begin{array}{l}\text { Physical features, consanguinity, } \\
\text { pathology }\end{array}$ & $\begin{array}{l}\text { MSH6, c.691delG p. (Val231Tyrfs*15), } \\
\text { homozygous }\end{array}$ & CMMRD \\
\hline 8 & GB & 12.11 & M & Physical features, pathology & $\begin{array}{l}\text { MSH6, c.691del p. (Val231Tyrfs*15) } \\
\text { and c.2906A > G p. (Tyr969Cys), } \\
\text { compound heterozygous }\end{array}$ & CMMRD \\
\hline $9^{b}$ & Glioma & 15.6 & $\mathrm{~F}$ & Physical features & $N F 1$, c. $6819+3 \mathrm{~A}>\mathrm{T}$ p.?, VUS & NF1 \\
\hline $10^{\mathrm{b}}$ & OPG & 3.8 & $\mathrm{~F}$ & Physical features & $\begin{array}{l}\text { NF1, c.3822_3823del p. (Phe- } \\
\text { 1275Profs*8) }\end{array}$ & NF1 \\
\hline $11^{\mathrm{b}}$ & OPG & 9.2 & M & Physical features & Work-up pending & $N F 1^{a}$ \\
\hline $12^{\mathrm{b}}$ & OPG, MPNST & 10.1 & $\mathrm{~F}$ & Physical features & Work-up pending & $N F 1^{a}$ \\
\hline $13^{\mathrm{b}}$ & HB & 1.0 & $\mathrm{~F}$ & Physical features & $\begin{array}{l}\text { KCNQ1OT1: TSS DMR LOM (IC2 } \\
\text { LOM) }\end{array}$ & BWS [10] \\
\hline $14^{\mathrm{b}}$ & HB & 11.6 & $\mathrm{~F}$ & Metabolic features & $\begin{array}{l}\text { TRMU, c.653G > T p. (Ser218Ala) } \\
\text { and c.1081_1082insAGGCTGTGC, } \\
\text { p. (Arg361Ala Val Arg), compound } \\
\text { heterozygous }\end{array}$ & Liver failure, transient infantile \\
\hline 15 & MG & 8.0 & $\mathrm{~F}$ & Pathology & $\begin{array}{l}\text { SMARCE1, c.959delC p. (Pro320Le- } \\
\text { ufs*122) }\end{array}$ & SMARCE1-related meningioma \\
\hline 16 & MG & 15.11 & M & Pathology & $\begin{array}{l}B A P 1, \text { c. } 2056+1 \mathrm{G}>\mathrm{A} \\
\text { r.2056_2057ins180 } \\
\text { p.Gly687Glufs*30 }\end{array}$ & $\begin{array}{l}\text { BAP1 tumor predisposition syn- } \\
\text { drome }\end{array}$ \\
\hline 17 & MDS & 3.1 & $\mathrm{~F}$ & $\begin{array}{l}\text { Immunodeficiency, physical features, } \\
\text { hematology, cytogenetics }\end{array}$ & $\begin{array}{l}\text { SAMD } 9, \text { c. } 4690 \mathrm{G}>\mathrm{C} \text { p. (Gly1564Arg), } \\
\quad \text { VUS }\end{array}$ & MIRAGE syndrome ${ }^{\mathrm{a}}$ \\
\hline $18^{\mathrm{b}}$ & MDS & 15.9 & M & Hematology & HAX1, c.130_131insA p. (Trp44*) & $\mathrm{SCN}[11]$ \\
\hline 19 & MDS & 17.4 & $\mathrm{~F}$ & Family history, pathology & GATA2, c. $1186 \mathrm{C}>\mathrm{T}$ p. $(\operatorname{Arg} 396 \operatorname{Trp})$ & GATA2 deficiency \\
\hline 20 & WT & 0.7 & $\mathrm{~F}$ & Lateralized overgrowth, pathology & upd(11)pat & BWS \\
\hline 21 & MDS & 1.9 & $\mathrm{~F}$ & $\begin{array}{l}\text { Immunodeficiency, physical features, } \\
\text { hematology, cytogenetics }\end{array}$ & SAMD9L, c.3584C > T p. (Ala1195Val) & Ataxia-pancytopenia syndrome \\
\hline 22 & RT & 1.1 & $\mathrm{~F}$ & Pathology & $\begin{array}{l}\text { nuc ish } 6(\mathrm{CEP} 6 \times 2), 22(\mathrm{RP} 11- \\
71 \mathrm{G} 19 \times 1, \mathrm{RP} 11-911 \mathrm{~F} 12 \times 1), \\
\text { heterozygous } S M A R C B 1 \text { deletion }\end{array}$ & RTPS \\
\hline 23 & SEGA & 6.4 & $\mathrm{~F}$ & Physical features, pathology & TSC2, c. $1513 \mathrm{C}>\mathrm{T}$ p. $\left(\operatorname{Arg} 505^{*}\right)$ & TSC \\
\hline $24^{\mathrm{b}}$ & TMPD & 0.2 & $\mathrm{~F}$ & Physical features, hematology & PTPN11, c.182A > G, p. (Asp61Gly) & NS \\
\hline $25^{\mathrm{b}}$ & TMPD & 0.0 & $\mathrm{~F}$ & Physical features & Trisomy 21 & DS \\
\hline $26^{\mathrm{b}}$ & TMPD & 0.0 & $\mathrm{~F}$ & Physical features & Trisomy 21 & DS \\
\hline 27 & Teratoma & 0.11 & M & Physical features & $M N X 1$, c.53delC p. (Pro18Hisfs*204) & Currarino syndrome \\
\hline
\end{tabular}

$A @ D$ age in years at cancer diagnosis, $A L L$ acute lymphoblastic leukemia, $A T$ ataxia teleangiectasia, $B W S$ Beckwith Wiedemann syndrome, $C A L S$ café-au-lait spots, $C M M R D$ constitutional mismatch repair deficiency, $C N$ cystic nephroma, $D S$ Down syndrome, $F H$ fibrous histiocytoma, GB glioblastoma, GIST gastrointestinal stromal tumor, HB hepatoblastoma, HPPS hereditary pheochromocytoma/paraganglioma syndrome, IC2 $L O M$ imprinting center 2 loss of methylation, $M D S$ myelodysplastic syndrome, $M G$ meningioma, MPNST malignant peripheral nerve sheet tumor, NF1 Neurofibromatosis type 1, NS Noonan syndrome, $O P G$ optic pathway glioma, $R T$ rhabdoid tumor, $R T P S$ rhabdoid tumor predisposition syndrome, $S C N$ severe congenital neutropenia, $S E G A$ subependymal giant cell astrocytoma, $T M P D$ transient myeloproliferative disease, TSC tuberous sclerosis, TSS DMR LOM transcription start site differentially methylated region, upd(11)pat paternal uniparental isodisomy of 11p15.5, VUS variant of uncertain significance (ACMG class 3), WT nephroblastoma

${ }^{\mathrm{a}}$ Clinically confirmed CPS diagnosis

${ }^{\mathrm{b}} \mathrm{CPS}$ diagnosis was known prior to the oncologic diagnosis or presentation to Hannover Medical School 
Table 2 Individuals diagnosed with CPS before the screening tool was introduced (2012-2016)

\begin{tabular}{|c|c|c|c|c|c|c|}
\hline No. & Cancer & Sex & A@D & Reason for evaluation & Genetic cause & CPS \\
\hline $1^{\mathrm{b}}$ & ALL & $\mathrm{F}$ & 7.7 & Physical features & Trisomy 21 & DS \\
\hline $2^{\mathrm{b}}$ & AML & M & 1.0 & Physical features & Trisomy 21 & DS \\
\hline $3^{\mathrm{b}}$ & AML & M & 3.1 & Physical features & Trisomy 21 & DS \\
\hline $4^{b}$ & AML & $\mathrm{F}$ & 3.1 & Physical features & Trisomy 21 & DS \\
\hline $5^{\mathrm{b}}$ & AML & M & 3.8 & Physical features & Trisomy 21 & DS \\
\hline 6 & AML & $\mathrm{F}$ & 11.7 & Physical features & $\begin{array}{l}\text { FANCA, c. } 45 \mathrm{G}>\text { A p. }(\text { Trp } 15 *), \text { and c.67delG p. } \\
\text { (Asp23Ilefs*23), compound heterozygous }\end{array}$ & FA \\
\hline 7 & $\mathrm{CRC}$ & M & 14.3 & Physical features, pathology & POLE, c $1231 \mathrm{G}>\mathrm{C}$ p. $($ Val411Leu $)$ & POLE deficiency [12] \\
\hline $8^{b}$ & OPG & $\mathrm{F}$ & 4.6 & Physical features & Work up pending & $\mathrm{NF} 1^{\mathrm{a}}$ \\
\hline $9^{\mathrm{b}}$ & OPG & $\mathrm{F}$ & 6.9 & Physical features & Work up pending & $N F 1^{a}$ \\
\hline $10^{\mathrm{b}}$ & OPG & M & 12.9 & Physical features & Work up pending & $\mathrm{NF} 1^{\mathrm{a}}$ \\
\hline 11 & OPG & $\mathrm{F}$ & 1.4 & Physical features & Work up pending & $\mathrm{NF} 1^{\mathrm{a}}$ \\
\hline $12^{\mathrm{b}}$ & OPG & $\mathrm{F}$ & 6.7 & Physical features & Work up pending & $N F 1^{a}$ \\
\hline $13^{\mathrm{b}}$ & MPNST & $\mathrm{F}$ & 6.6 & Physical features & Work up pending & $\mathrm{NF} 1^{\mathrm{a}}$ \\
\hline $14^{\mathrm{b}}$ & HD & M & 11.7 & Immunodeficiency & $\begin{array}{l}\text { PIK3CD, c. } 1689+9 \mathrm{G}>\mathrm{A} \text { and c } .3061 \mathrm{G}>\mathrm{A} \mathrm{p} . \\
\text { (Glu1021Lys), compound heterozygous }\end{array}$ & Activated PIK3CD syndrome \\
\hline 15 & MDS & $\mathrm{F}$ & 13.3 & Pathology & FANCA, c.1814_1815delAG p. (Glu605Valfs*7) & FA \\
\hline 16 & NBL & $\mathrm{F}$ & 0.11 & Pathology & $A L K$, c. $3824 \mathrm{G}>$ A p. $(\operatorname{Arg} 1275 \mathrm{Gln})$ & NBL predisposition \\
\hline $17^{\mathrm{b}}$ & RMS & $\mathrm{F}$ & 2.2 & Family history & TP53, c.309C > G p. (Tyr103*) & LFS \\
\hline 18 & TT & $\mathrm{F}$ & 12.2 & Pathology & DICER1, c.2920dupA p. (Thr974Asnfs*6) & DICER1 syndrome \\
\hline $19^{\mathrm{b}}$ & TMPD & M & 0.0 & Physical features & Trisomy 21 & DS \\
\hline $20^{\mathrm{b}}$ & TMPD & M & 0.0 & Physical features & Trisomy 21 & DS \\
\hline $21^{\mathrm{b}}$ & TMPD & M & 0.2 & Physical features & Trisomy 21 & DS \\
\hline $22^{\mathrm{b}}$ & TMPD & M & 0.2 & Physical features & Trisomy 21 & DS \\
\hline $23^{\mathrm{b}}$ & $\mathrm{RB}$ & $\mathrm{F}$ & 1.10 & Physical features & $\begin{array}{l}\operatorname{arr}[\text { GRCh37] 13q14.13q21.33 } \\
\left(45943304 \_68903406\right) \times 1\end{array}$ & $13 q$ deletion syndrome \\
\hline 24 & $\mathrm{cMX}$ & M & 15.1 & Pathology & arr [GRCh37] 17q24.2 (66501525_66512418) ×1 & Carney Complex [13] \\
\hline
\end{tabular}

$A @ D$ age in years at cancer diagnosis, $A L L$ acute lymphoblastic leukemia, $C A L S$ café-au-lait spots, $C R C$ colorectal carcinoma, $D S$ Down syndrome, FA Fanconi anemia, HD Hodgkin disease, LFS Li Fraumeni syndrome, MDS myelodysplastic syndrome, MPNST malignant peripheral nerve sheet tumor, $c M X$ cardial myxoma, $N B L$ neuroblastoma, $N F 1$ neurofibromatois type $1, O P G$ optic pathway glioma, $R B$ retinoblastoma, $R M S$ rhabdomyosarcoma, $T T$ thyroid tumor, $T M P D$ transient myeloproliferative disease

${ }^{\mathrm{a}}$ Clinically confirmed CPS diagnosis

${ }^{\mathrm{b}} \mathrm{CPS}$ diagnosis was known prior to the oncologic diagnosis or presentation to Hannover Medical School

and positive predictive values and sensitivity/specificity are unknown, it is likely that a small number of cases of CPS will be missed using clinical approaches.

Supplementary Information The online version contains supplementary material available at https://doi.org/10.1007/s10689-021-00233-5.

Author contributions The study was concepted by CPK, TR, AB and MS. Data and material of the study was generated by CPK, TR, BD. Data collection was performed by MS, interpretation and analysis was conducted by MS, with the support of CPK and TR. MS wrote the manuscript with the support of CPK and TR. The paper was edited by all authors. All authors have read and approved the final manuscript.

Funding C.P.K has been supported by the Deutsche Kinderkrebsstiftung (DKS2017.02), and BMBF ADDRess (01GM1909A). T.R. has been supported by BMBF MyPred (01GM1911B). Open Access funding enabled and organized by Projekt DEAL.
Data availability Raw data and material and processed data are held within the Department of Pediatric Hematology and Oncology at Hannover Medical School.

\section{Compliance with ethical standards}

Conflict of interest The authors indicate no potential conflicts of interest.

Ethical approval The study was approved by the ethical review board at Hannover Medical School.

Informed consent A consent was not necessary in this analysis.

Open Access This article is licensed under a Creative Commons Attribution 4.0 International License, which permits use, sharing, adaptation, distribution and reproduction in any medium or format, as long as you give appropriate credit to the original author(s) and the source, 
provide a link to the Creative Commons licence, and indicate if changes were made. The images or other third party material in this article are included in the article's Creative Commons licence, unless indicated otherwise in a credit line to the material. If material is not included in the article's Creative Commons licence and your intended use is not permitted by statutory regulation or exceeds the permitted use, you will need to obtain permission directly from the copyright holder. To view a copy of this licence, visit http://creativecommons.org/licenses/by/4.0/.

\section{References}

1. Sylvester DE, Chen Y, Jamieson RV, Dalla-Pozza L, Byrne JA (2018) Investigation of clinically relevant germline variants detected by next-generation sequencing in patients with childhood cancer: a review of the literature. J Med Genet 55(12):785-793. https://doi.org/10.1136/jmedgenet-2018-105488

2. Zhang J, Walsh MF, Wu G et al (2015) Germline mutations in predisposition genes in pediatric cancer. N Engl J Med 373(24):2336-2346. https://doi.org/10.1056/NEJMoa1508054

3. Grobner SN, Worst BC, Weischenfeldt J et al (2018) The landscape of genomic alterations across childhood cancers. Nature 555(7696):321-327. https://doi.org/10.1038/nature25480

4. Jongmans MC, Loeffen JL, Waanders E et al (2016) Recognition of genetic predisposition in pediatric cancer patients: an easy-touse selection tool. Eur J Med Genet 59(3):116-125. https://doi. org/10.1016/j.ejmg.2016.01.008

5. Ripperger T, Bielack SS, Borkhardt A et al (2017) Childhood cancer predisposition syndromes-A concise review and recommendations by the Cancer Predisposition Working Group of the Society for Pediatric Oncology and Hematology. Am J Med Genet A 173(4):1017-1037. https://doi.org/10.1002/ajmg.a.38142

6. Goudie C, Cullinan N, Villani A et al (2018) Retrospective evaluation of a decision-support algorithm (MIPOGG) for genetic referrals for children with neuroblastic tumors. Pediatr Blood Cancer 65(12):e27390. https://doi.org/10.1002/pbc.27390

7. Hopman SM, Merks JH, de Borgie CA et al (2013) The development of a clinical screening instrument for tumour predisposition syndromes in childhood cancer patients. Eur J Cancer 49(15):3247-3254. https://doi.org/10.1016/j.ejca.2013.06.015
8. Erdmann F, Kaatsch P, Grabow D, Spix C (2020) German childhood cancer registry: annual report 2019 (1980-2018). Institute of Medical Biostatistics, Epidemiology and Informatics (IMBEI) at the University Medical Center of the Johannes Gutenberg University Mainz 2020

9. Zeharia A, Shaag A, Pappo O et al (2009) Acute infantile liver failure due to mutations in the TRMU gene. Am J Hum Genet 85(3):401-407. https://doi.org/10.1016/j.ajhg.2009.08.004

10. Coktu S, Spix C, Kaiser M et al (2020) Cancer incidence and spectrum among children with genetically confirmed Beckwith-Wiedemann spectrum in Germany: a retrospective cohort study. Br J Cancer 123(4):619-623. https://doi.org/10.1038/ s41416-020-0911-x

11. Klein C, Grudzien M, Appaswamy G et al (2007) HAX1 deficiency causes autosomal recessive severe congenital neutropenia (Kostmann disease). Nat Genet 39(1):86-92. https://doi.org/10. 1038/ng1940

12. Wimmer K, Beilken A, Nustede R et al (2017) A novel germline POLE mutation causes an early onset cancer prone syndrome mimicking constitutional mismatch repair deficiency. Fam Cancer 16(1):67-71. https://doi.org/10.1007/s10689-016-9925-1

13. Behnert A, Ripperger T, Jack T, Franke D, Horke A, Kratz C (2016) Linksatriale Raumforderung und Lentigines. Monatsschr Kinderheilkd 164:1064-1067

14. Chen DH, Below JE, Shimamura A et al (2016) Ataxia-pancytopenia syndrome is caused by missense mutations in SAMD9L. Am J Hum Genet 98(6):1146-1158. https://doi.org/10.1016/j.ajhg.2016. 04.009

15. Narumi S, Amano N, Ishii T et al (2016) SAMD9 mutations cause a novel multisystem disorder, MIRAGE syndrome, and are associated with loss of chromosome 7. Nat Genet 48(7):792-797. https://doi.org/10.1038/ng.3569

16. Waszak SM, Robinson GW, Gudenas BL et al (2020) Germline Elongator mutations in Sonic Hedgehog medulloblastoma. Nature 580(7803):396-401. https://doi.org/10.1038/s41586-020-2164-5

Publisher's Note Springer Nature remains neutral with regard to jurisdictional claims in published maps and institutional affiliations. 